\title{
Observations from community care for serious mental illness during a controlled study
}

\author{
Joseph Connolly, Isaac Marks, Robin Lawrence, \\ Gary McNamee and Matt Muijen
}

\begin{abstract}
A controlled study of community care in serlous mentol Illiness (SMI) was carried out. Patients with SMII were randomised to have hoepiltal care or be looked affer by a community peychlaticic care team in a Dally Luving Programme (DLP). The day-to-day work of a clinical team with the dificulties encountered in dellvering community poychlatilic core in an inner clty is described. There were seven deaths from sell-horm duing the 45-month study. One DLP pattient commilted homicide. An ordeal by media following this and the sulcides ore described. Leseons bant include the need for the community care team to be responsible for discharge from any in-patient phases and for attention to tecom morale, especiolly during adversity, and to fime spent working under pressure.
\end{abstract}

In recent decades there has been worldwide concern on what the exact function is of a hospital psychiatric bed in mental health care. especially for those with serious mental illness (SMI). Many countries have run down and closed large mental hospitals and resettled their former patients in more natural settings, most of whom do not wish to return to large mental hospitals. Many disengage from psychiatric care.

The care of SMI (usually schizophrenia, severe depression, and mania) has often been studied in settings alternative to that of in-patient care. Randomised controlled trials have compared community with in-patient care (e.g. Burns et al, 1993) and controlled contrasts have been made of day $v$. in-patient care (Creed et al, 1990), and of community emergency service $v$. hospital care (Merson et al, 1992).

Conclusions from controlled studies (reviewed by Marks \& Scott, 1990) and from uncontrolled ones were consistent. They found that in-patient care nowhere outperformed good alternatives, e.g. in Madison and in Sydney. It also cost slightly less - between 4 and $25 \%$.

A model of care for SMI emerged, sharing elements with those for other chronic conditions like diabetes. People with SMI require not longterm in-patient care but a daily support network to offset their chronic deficits and deal with crises. A comprehensive service should include 24-hour access for crisis resolution, out-patient clinics, day care, some long- and short-term inpatient facilities, and specialised living and work arrangements. SMI patients require continuing support and regular contacts concerning housing, work, finance, socialising, hyglene, physical health and medication. Determined follow-up is essential to prevent relapse of disengaging patients.

A Daily Living Programme (DLP) of activities is needed for a more satisfactory existence. Individual problems have to be delineated and dealt with. The outcome of the first European randomised controlled comparison of DLP care with standard hospital care over 45 months was described elsewhere (Audini et al, 1994; Knapp et al, 1994; Marks et al, 1994). The present paper outlines the DLP's clinical practice with 92 out of the 189 SMI patients randomised to home-based DLP care in the controlled study.

\section{The study}

In 1986 the Department of Health and Social Security (DHSS) invited bids for funds of up to $\$ 400000$ per region for innovations in community psychiatric care. Such a bid was made from the Bethlem-Maudsley Hospital to try to replicate the earlier randomised controlled studies in the USA and Australia, conducted in very different settings from the inner-London catchment area of South Southwark (population 136000) - the eighth most deprived borough in Britain.

The bid attracted not $\$ 400000$ but an award of $\$ 272000$. The project therefore had to be resource-driven, not needs-driven. This posed the problem - how many staff and of what disciplines could be employed to cover which hours of the working week? This, for a sevenday service, turned out to be one psychiatrist 
(senior registrar, first MM, then $\mathrm{RL}$ and then $\mathrm{Dr}$ Vik Watts), seven psychiatric nurses (managed by GM), a social worker for 14 months, and a secretary/coordinator. One nursing post was occupied by a senior occupational therapist in the second and third years of the project. A consultant psychiatrist (JC) altered his working week to devote two sessions to head the Daily Living Programme team (DLP).

The hours that could be covered by the staff funded were initially 8.30 a.m. to 9 p.m., Monday to Friday, and 9 a.m. to 5 p.m., Saturdays and Sundays. Every night a team member was on-call by telephone for advice, with the ever-open Emergency Clinic for problems which could not be contained at home. In the original DLP study patients had home-based care for a mean 20 months after intake. Subsequently a randomised half of those DLP patients continued in DLP care for a mean of a further 27 months (the other half went into standard hospital-based care). Five and a quarter years elapsed from intake of the first patient in October 1987 to closure of the DLP in December 1992.

At entry all 189 patients were judged to have SMI, lived in South Southwark (or had credible associations with it, if for example, they were of no fixed abode), were aged 17 to 64 , and had no acute or chronic brain syndrome or primary addiction. A decision had been made independently (in almost all at the Emergency Clinic) that admission was necessary. They were randomised to be admitted for standard hospital-based care ( $n=97$, controls) or to be looked after by the DLP team $(n=92)$ caring for people mostly in their own homes.

Randomisation was stratified according to whether patients were would-be first admissions (which, it was thought, might have a good prognosis with any treatment - this turned out not to be the case) or readmissions. Half of all would-be first admissions were randomised to DLP care. However, only $20 \%$ of SMI patients who had had previous admissions were randomised to DLP care, to avoid swamping the DLP service and to take account of the rest of the hospital's needs. Both cohorts had an independent evaluation funded from the Department of Health (the then DHSS) (Muijen \& et al, 1992a. $1992 b)$. The subsequent withdrawal phase was described elsewhere (Audini et al, 1994; Marks, 1995).

\section{The work of the DLP team}

None of the team, except the consultant psychiatrist and the senior registrar, had previously worked in the community. After a short induction period the DLP began to take on the new patients who had been randomised to its care and started to learn on the job. The care was problemcentred. A key worker of whatever discipline worked out with the patient what the chief problems were and goals to deal with them, and agreed statements to describe them.

A problem, rated $0-8$ on severity, might be: "Repeated discontinuation of neuroleptic medication with recurrence within weeks of delusions and auditory hallucinations".

A goal, rated 0-8 on difficulty of achievement. might be: "To accept depot injection of $40 \mathrm{mg}$ of flupenthixol intramuscularly every two weeks for six months in the first instance".

The therapeutic input was measured under the headings: face-to-face contact with patient, telephone time, travelling time, and face-to-face contact with others. This was to allow the direct therapeutic input (and so cost) to be calculated for each patient. Indirect costs were also measured (Knapp et al, 1994).

After extensive experience the team described the DLP's operations in $\mathbf{3 8}$ points.

The DLP provides for its patients:

Monitoring of clinical and social state

Timely involvement of other relevant agencies and persons

Relationships with team members to help lessen disability

Easy access

Close attention to and an understanding of their experience, behaviour, strengths, weaknesses and life settings

Admission to hospital, continuing contact and planning

Forward thinking

Occasional meals, clothing, furniture and loans

Sometimes an unshared goal, e.g. detention under the Mental Health Act

Counselling

Models of understanding of their own predicament.

The DLP advocates for its patients with:

Police, lawyers, courts, prison officials as appropriate

Public utilities over arrears and continuing supply

Social security officials for entitled benefits

Housing departments \& associations, hotels and hostels, relatives, friends and landlords for housing needs, arrears and future payments

General practitioners, hospital staff and social services

Employers

Shops and café workers 
Voluntary organisations and clergy

Local authorities over taxes, bus passes, etc

Neighbours, relatives and friends.

The DLP prompts its patients:

Towards better nutrition, hygiene, physical health and budgeting to attend important meetings.

The DLP persuades its patients, if at all possible, to:

Accept therapeutic interventions judged as best serving patients' interests

Decreasing mind-altering substance abuse.

The DLP negotiates with its patients on:

Contacts

Problems and targets

Means to solve problems and achieve targets.

The DLP measures in its patients at entry into care, during it and on discharge from it:

Salient problems and their severity Difficulty in achieving the negotiated targets

Team time input face-to-face, travelling, on phone.

The DLP ensures that:

It acts professionally always

Its records help the evaluation of its work and could be creditably scrutinised by the courts Medication is delivered and monitored

Its staff works with an awareness of personal safety

It communicates its working and results to interested others

It does not burn-out and looks for professional development and wider clinical experience

It fosters good relationships within the team and with others crucial to its remit.

\section{Findings}

The main findings were that compared to controls:

(a) the duration (but not number) of admissions for DLP patients fell by $80 \%$, but only as long as the DLP team was in charge of any in-patient phase

(b) DLP patients became marginally superior on clinical and social scales late at month
20, but not thereafter and most remained unemployed

(c) DLP patients and their relatives were more satisfied with care from month 11 to month 45

(d) DLP care cost somewhat less

(e) DLP care did not reduce the number of deaths.

Not everything went smoothly. While visiting a patient a DLP team member was attacked with a carving knife and another was mugged in broad daylight on a main road. Two DLP team members had to barricade themselves in the team's office to prevent a psychotic patient from attacking them.

In the 20 months after trial entry, of the 92 DLP patients, one murdered a neighbour's child and three died from self-harm. During this time there were two deaths from self-harm among the 97 controls. In the next $2 \frac{1}{2}$ years one patient committed suicide shortly after passing from DLP to control care, and one of the original controls committed suicide at four years postentry.

\section{Comment}

\section{Novelty tends to attract attention}

Fourteen months after the murder and two years after the DLP study had begun, a reporter on a national tabloid newspaper telephoned about the tragedies. She was well-informed. Extenstve media coverage followed. It was not laudatory. An MP asked the House of Commons when the government would stop funding its experiment in human lives. In the main evening TV news, questions faced included "Don't you think that with this number of tragedies this way of looking after patients has been discredited?" The fact that at the time there was not even a trend in differences between the groups carried little conviction with the general public.

Alarmed by the publicity, the Ethical Committee (Research) of the Hospital and Institute of Psychiatry which had approved the study ordered an enquiry. This was carried out by a director of nursing services and a consultant psychiatrist unconnected to the DLP, with a lay chairman who was a member of the health authority. The enquiry exonerated the DLP from all blame and ethical approval was continued.

During the same 27 months that the DLP had been working it emerged that there had been 18 suicides quite outside the study among patients who were in-patients of the hospital at the time or had been recently discharged. This high suicide rate had not been previously realised. Questions are not asked as incistvely of established methods of treatment, however unsatisfactory, compared 
with those asked of a novel form of treatment. All suicides in the Joint Hospital are now subjected to audit.

\section{A natural experiment}

After its enquiry, the Ethical Committee (Research) stipulated that any DLP patients. who were admitted should be cared for by the ward medical as well as nursing teams. (Previous nursing care had been provided by the ward but most of the medical input and problem-centred nursing care had come from the DLP). After this ruling that the ward team control the length of stays their durations trebled. If time in hospital is to be lessened and patients returned early to care within their own homes, the team caring for them at home must be able to influence the duration of admission.

\section{The randomised withdrawal phase}

To give it credit, the confidence of the Department of Health was not shaken by these events. The funding of the DLP should have ended after three years. However, in Madison, Wisconsin, discont1nuation of DLP-type care (titled the Training in Community Living') had led to the disappearance of all gains by 14 months. The Department partfunded a design in which a half of the initially randomised DLP cohort was further randomised to its continuing care and half returned to standard hospital care. The DLP team was slimmed in line with its new responsibilities. Morale fell, however, after the hospital enquiry and with future funding uncertain. The emphasis on the problem-oriented mode of DLP care diminished and the DLP team was not allowed responsibility for any in-patient phase. Only two of the entire DLP team (JC and Ian Moran) stayed with it throughout its $5 \frac{1}{4}$ years.

Independent evaluation of the withdrawal phase from months 30-45 after trial entry was completed on funding from the Wolfson Foundation (Audini et al, 1994; Marks, 1995). The clinical gains of DLP v. control care attenuated and the number of in-patient bed days used rose to that of controls (which fell compared to that in the earlier phase). Patient and relative satisfaction, however, continued to be significantly greater than in the control group.

\section{Conclusion}

Only until 20 months post-trial entry for SMI was it possible to reduce in-patient bed use by a mottivated team giving home-based care which was preferred by patients and their relatives. At no time was it outperformed by standard hospital care. Critical media attention can be expected if there are tragedies. Tragedies are likely because SMI patients, whether admitted or in community care, are often dangerous to themselves and to others. The fall in clinical gains after month 20 (in spite of patients' and relattves' continuing preferences) showed that, if maximum gains are to be sustained indefinitely, more careful nurturing of home-based care than we managed is necessary. The home-based team needs to be responsible for crisis in-patient admissions needed by their patients.

\section{Acknowiedgements}

The Department of Health funded most of the study, and the Wolfson Foundation funded evaluation of the withdrawal phase. Thanks are due to colleagues who shared in the Daily Living Programme at some time: Ian Moran, Janet Matiba. Sean McCoy, Diane Walker, Sara Tiplady. Alistair Park, Cathy Fallon, Alan Patterson, Guy Caplan, Jon Akoto, Joanna Sandwell, Sean Fletcher, Melanie Barlow, Janine James, Sarah Lyon-Maris, Sarah Bellamy, Harper Brown, Barbara Soal and Martin Rainbow, Dr M. Marlowe, Dr P. Mascunan and Dr V. Watts. Bernard Audini made helpful comments on the manuscript.

\section{References}

AUdIN, B., MARKS, I. M., LAWRENCE, R. E., et al (1994) Homebased v. in/outpatient care for serious mental illness: phase II of a controlled study. British Joumal of Psychiatry. 165, 204-210.

Burns, T., Bendsmoore, A. Bhat, A. V., et al (1993) A controlled trial of home-based acute psychiatric services. British Joumal of Psychiatry. 163, 49-61.

Creed, F., Black. D., ANTHONY, P., et al (1990) Randomised controlled trial of day patient versus inpatient peychiatric treatments. British Medical Journal. 800 . 1033-1037.

KNAPP, M., BEEchaM, V., KOUTSOCEORGOPOLOU, V., et al (1994) Service use \& costs of home-based v. hospital based care for people with serious mental illness. Brttish Journal of Psychiatry. 165, 195-203.

MARKS, I. M. (1995) Synopsis of the dally itving program for the seriously mentally ill: a controlled comparison of home-vs hospital-based care. In Community Treatments for Acute Psychiatric Illness. (eds. F. Creed and P. Tyrer). Cambridge: Cambridge Untversity Press.

- \& Scort, R. (1990) Mental Health Care Deltuery: Innovations, Impediments and Implementation Cambridge: Cambridge Untversity Press.

-. Connouy, J., MuJEn, M., et al (1994) Home-based v. hospital based care for people with serfous mental illness. British Joumal of Psychiatry. 166, 179-194.

MERSON. S.. TYReR, P.. ONYETT, S., et al (1992) Earty intervention in poychiatric emergencies: a controlled clinical trial. Lancet, $359.1311-1314$. 
MurJen, M., Mnrks, I. M., Connouy, J., et al (1992a) The Dally Ltuing Program: Preliminary comparison of community v. hospital-based treatment for the seriously mentally ill facing emergency admission. Brttish Journal of Psychiatry, 160, 379-384.

- - - - . et al (1992b) Home-based care vs standard hospital-based care for the severely mentally ill: shortterm outcome. British Medical Joumal, so4, 749-754.

-Joseph Connolly, Consultant Psychiatrist, Isaac Marks, Professor of Expertmental Psychopathology:
Robin Lawrence, Senior Registrar, Matt Muijen, Senior Registrar. Bethlem Royal \& Maudsley Hospital, and Instthute of Psychiatry, London SE5 8AF, and Gary McNamee, Lambeth Mental Health Community Trust

*Correspondence

\title{
DEFEAT DEPRESSION CAMPAIGN FUN RUN
}

\section{BATTERSEA PARK, LONDON}

\author{
11 a.m. Sunday 28th April 1996 \\ Entry Fee $£ 3.00$ Distance $2 \frac{1}{2} 2$ miles
}

All proceeds to go towards the production of Defeat Depression Campaign educational material

For an entry form please contact Christine Gear on 01712352351 ext 131

A National Campaign organised by The Royal College of General Practitioners 